Tema: Produtos Metálicos Ferrosos

\title{
ESTUDO DA INFLUÊNCIA DA TEMPERATURA DE RECOZIMENTO INTERCRÍTICO NAS PROPRIEDADES DE UM AÇO DUAL-PHASE*
}

Luara da Costa Morais ${ }^{1}$ Rodrigo Magnabosco 2

\section{Resumo}

O objetivo deste trabalho é avaliar a influência da temperatura de recozimento intercritíco na microestrutura e nas propriedades de um aço dual-phase. Para isto, amostras do aço em estudo foram recozidas intercriticamente a temperaturas entre 720 e $740^{\circ} \mathrm{C}$. A quantificação da martensita foi realizada por estereologia quantitativa sobre imagens obtidas por sinal de elétrons secundários. Ensaios de tração e de estampabilidade foram realizados no material tratado e na condição de partida. Os resultados da quantificação mostraram aumento na fração de martensita com o aumento da temperatura de tratamento. Para o estudo da influência da microestrutura no comportamento mecânico, foi relacionada a fração de martensita com as propriedades mecânicas obtidas nos ensaios de tração e estampabilidade. As amostras recozidas intercriticamente apresentaram aumento nos limites de resistência e escoamento e diminuição dos alongamentos, total e uniforme, com o aumento da fração de martensita. A amostra de partida apresentou frações de martensita similares às observadas para a tratada a $740^{\circ} \mathrm{C}$, entretanto com valores de resistência e escoamento inferiores e alongamento superior, sugerindo influência da morfologia nas respostas mecânicas do material. O material como recebido apresentou a melhor combinação entre resistência, alongamento e estampabilidade indicando que esta condição é mais indicada para o setor automotivo.

Palavras-chave: Aço dual-phase; Recozimento intercrítico; Propriedades mecânicas; Estambabilidade.

\section{STUDY OF THE INTERCRITICAL ANNEALING TEMPERATURE INFLUENCE ON THE PROPERTIES OF A DUAL-PHASE STEEL}

\begin{abstract}
The aim of this work is to evaluate the annealing temperature influence on the microstructure and properties of a dual-phase steel. Specimens were heat treated in a range of temperatures from 720 to $740^{\circ} \mathrm{C}$. The martensite quantification was done by quantitative stereology over images obtained by secondary electron signal. Tension and formability tests were made on the treated samples and on as received material. The quantification results shown that the martensite fraction increased with the intercritical annealing temperature. For the study of the microstructure influence on the mechanical behavior of the steel, the martensite fraction was related to the mechanical properties obtained on the tensile and Erichsen formability tests. For the treated samples it was observed an increase in the yield and tensile strength values and a decrease in the total and uniform elongation values, with the increase of the martensite fraction. The as received material shown martensite fractions similar as those treated at $740^{\circ} \mathrm{C}$, however with lower tensile and yield strengths and superior elongation value, suggesting a morphology influence on the mechanical behavior of the material. The as received material had shown the best combination between strength, elongation and formability, suggesting that this condition is the most indicated for the automotive segment.
\end{abstract}

Key words: Dual-phase steel; Intercritical annealing; Mechanical properties; Formability.

Graduanda, curso de Engenharia de Materiais, Centro Universitário da FEl, São Bernardo do Campo, SP, Brasil; luaracmorais@yahoo.com.br.

2 Prof. Dr., Departamento de Engenharia de Materiais, Cento Universitário da FEI, São Bernardo do Campo, SP, Brasil; rodrmagn@fei.edu.br.

* Contribuição técnica ao 69ำ Congresso Anual da ABM - Internacional e ao 14ํㅡㄹ ENEMET - Encontro Nacional de Estudantes de Engenharia Metalúrgica, de Materiais e de Minas, 21 a 25 de julho de 2014, São Paulo, SP, Brasil. 


\section{INTRODUÇÃO}

Pertencentes ao grupo de aços de alta resistência, os aços dual-phase foram desenvolvidos principalmente para atender o setor automotivo. Por serem compostos por uma matriz ferrítica com ilhas de martensita dispersas nesta matriz, estes aços apresentam uma ótima combinação entre resistência mecânica e alongamento. A boa resistência mecânica é atribuída a resistência da martensita e ao diminuto tamanho de grão da ferrita, já o bom alongamento está relacionado novamente ao diminuto tamanho de grão, gerando maior alongamento uniforme, propiciando aumento da estampabilidade destes aços [1,2].

Os aços dual-phase podem ser obtidos pelo processo de laminação controlada, recozimento contínuo ou simplesmente pelo tratamento térmico de recozimento intercrítico, onde o aço é aquecido em um campo onde coexistem as fases ferrita $(\alpha)$ e austenita $(\gamma)$, sendo resfriado com uma velocidade rápida suficiente para transformação da austenita em martensita. Davies e Magee [3] reportam que esses aços são uns dos mais interessantes entre os aços de alta resistência, pois fornecem boa resistência aliada com boa ductilidade, permitindo redução de peso de estruturas [3,4].

Devido às boas propriedades atribuídas a esses aços, eles são utilizados principalmente na indústria automobilística, onde se busca alta resistência aliada a boa tenacidade e estampabilidade [3-5]. Estudos mostram que a utilização dos aços dual-phase na área automotiva está sendo uma alternativa na busca de aumento de eficiência [6].

Contudo, estudos mostram que os valores de resistência e ductilidade apresentados por esses aços variam com a fração de martensita presente. Speich e Miller [7] realizaram tratamentos isotérmicos a temperaturas entre $740^{\circ} \mathrm{C}$ e $780^{\circ} \mathrm{C}$, buscando a estrutura dual-phase em aços baixo-carbono: os tratamentos foram realizados em aços com teores de $\mathrm{C}$ variando entre $0,005 \%$ e $0,29 \%$, visando diferentes frações de martensita. Os autores observaram que o aumento na fração de martensita levou a um aumento não linear no limite de resistência a tração e no limite de escoamento.

Assim como Speich e Miller [7] estudos de Forgas e Magnabosco [8] mostram comportamento não linear na variação da resistência a tração com a fração de martensita: os autores realizaram tratamentos entre $715^{\circ} \mathrm{C}$ e $800^{\circ} \mathrm{C}$ em amostras de um aço com $0,075 \% \mathrm{C}-1,08 \% \mathrm{Si}-1,15 \% \mathrm{Mn}$. Os resultados reportados por Forgas e Magnabosco [8] mostram duas inclinações na variação do limite de resistência com a fração de martensita. Na faixa de 18 a $26 \%$ de martensita o aumento na resistência é acentuado, indicando que este aumento pode estar relacionado com o aumento na fração de martensita, já na faixa de 8 a 18\% de martensita a variação na resistência é pouca, indicando que por mais que a fração da fase resistente aumente, a diminuição do $\mathrm{C}$ dissolvido na austenita e portanto na martensita com 0 aumento da temperatura afeta negativamente $o$ aumento da resistência neste trecho.

Além do limite de resistência, Forgas e Magnabosco [8] também avaliaram as propriedades de limite de escoamento. Diferentemente do limite de resistência os autores avaliaram que a variação do limite de escoamento em função da fração de martensita ocorre linearmente, sugerindo que esta propriedade depende somente da fração de martensita presente. Segundo os autores, este comportamento é observado pois a deformação destes aços ocorre em três estágios, sendo primeiro relacionado a deformação elástica da ferrita, o segundo a deformação plástica da ferrita e elástica da martensita e o terceiro a deformação plástica da ferrita e

\footnotetext{
* Contribuição técnica ao 69ำ Congresso Anual da ABM - Internacional e ao 14ํㅡㄹ ENEMET - Encontro Nacional de Estudantes de Engenharia Metalúrgica, de Materiais e de Minas, 21 a 25 de julho de 2014, São Paulo, SP, Brasil.
} 
martensita. Em se tratando ao limite de escoamento, este é atingido quando o material encontra-se entre os estágios 1 e 2 , onde apenas a matriz ferritíca se deforma.

Visto a importância dos aços dual-phase para o setor automotivo e a influência dos parâmetros de tratamento no desempenho destes aços, o estudo do comportamento mecânico relacionado com a microestrutura faz-se necessário. Assim, este trabalho tem por objetivo o estudo da influência da temperatura de recozimento intercrítico nas propriedades mecânicas e na estampabilidade do aço dual-phase LITEC800DP da siderúrgica Ruukki

\section{MATERIAL E MÉTODOS}

O material em estudo é uma chapa de aço bifásico LITEC800DP, obtido nas dimensões de $1600 \mathrm{~mm}$ de comprimento x $800 \mathrm{~mm}$ de largura x 1,5 mm de espessura. Foi retirada uma amostra de aproximadamente $30 \times 30 \mathrm{~mm}$ para análise química realizada por espectrometria de emissão óptica, e a análise segue apresentada na Tabela 1.

Tabela 1 - Composição química (\%massa) do aço em estudo.

\begin{tabular}{cccccccccc}
\hline $\mathrm{C}$ & $\mathrm{Si}$ & $\mathrm{Mn}$ & $\mathrm{Cr}$ & $\mathrm{Mo}$ & $\mathrm{Ni}$ & $\mathrm{Cu}$ & $\mathrm{Nb}$ & $\mathrm{Ti}$ & $\mathrm{V}$ \\
\hline 0,170 & 0,272 & 1,830 & 0,560 & 0,013 & 0,055 & 0,041 & 0,023 & 0,005 & 0,011 \\
\hline
\end{tabular}

A partir da chapa foram produzidos 12 corpos de provas de tração segundo a ASTM E8M-13 a [9], nas dimensões $12,5 \mathrm{~mm}$ de largura, $50 \mathrm{~mm}$ de comprimento de referência e $1,5 \mathrm{~mm}$ de espessura, e 4 tiras nas dimensões de $300 \mathrm{~mm}$ de comprimento $\times 40 \mathrm{~mm}$ de largura $\times 1,5 \mathrm{~mm}$ de espessura. Três conjuntos de três corpos de prova e três tiras foram separados para os tratamentos térmicos, e os corpos de provas e a tira restante foram utilizados para caracterização do material como recebido. As temperaturas de recozimento intercrítico foram determinadas pela simulação das frações das fases presentes em função da temperatura, apresentada na Figura 1. A simulação foi realizada em ThermoCalc ${ }^{\circledR}$ utilizando a composição química do aço em estudo e a base de dados TCFE6. Foram determinadas 3 temperaturas para realização dos tratamentos térmicos. Para a determinação da primeira temperatura foi considerado $10^{\circ} \mathrm{C}$ acima da última temperatura onde se observou a presença da cementita, sendo esta temperatura aproximadamente $720^{\circ} \mathrm{C}$. O limite superior estudado, onde se têm aproximadamente $50 \%$ de martensita, foi determinado como $740^{\circ} \mathrm{C}$, e a condição intermediária em $730^{\circ} \mathrm{C}$.

* Contribuição técnica ao $69^{\circ}$ Congresso Anual da ABM - Internacional e ao 14ํㅡㄹ ENEMET - Encontro Nacional de Estudantes de Engenharia Metalúrgica, de Materiais e de Minas, 21 a 25 de julho de 2014, São Paulo, SP, Brasil. 

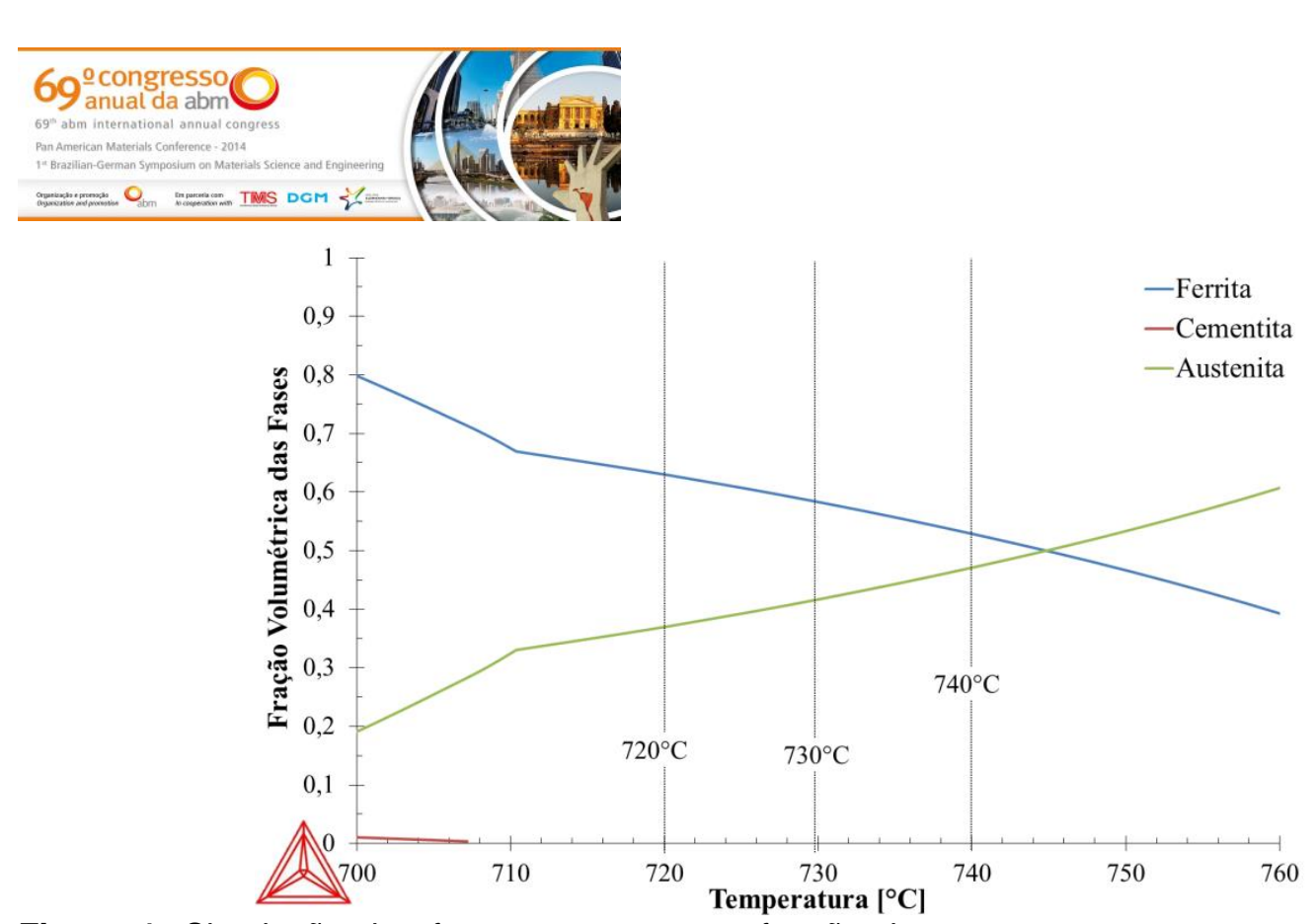

Figura 1. Simulação das fases presentes em função da temperatura para a composição química estudada.

Os corpos de prova e as tiras cortadas foram recozidas intercriticamente nas temperaturas previamente determinadas, o tempo de tratamento foi de 30 minutos com posterior resfriamento em água. Foi utilizado forno tubular para tratamento dos corpos de prova e forno poço para tratamento das tiras, ambos sob vácuo.

Três corpos de prova tratados a cada temperatura e três do material como recebido foram submetidos ao ensaio de tração segundo a norma E8M - 13 ${ }^{\mathrm{a}}$ [9]. Os ensaios de tração foram realizados em máquina de tração Tinius Olsen com capacidade máxima de 60 toneladas. Determinaram-se pelo ensaio de tração o limite de escoamento, o limite de resistência e os alongamentos total e uniforme, estes dois últimos com base num comprimento inicial de $50 \mathrm{~mm}$. Foi realizado ensaio de embutimento Erichsen, conforme norma ASTM E643-09 [10], nas tiras tratadas e na tira do material como recebido.

Foi realizada ainda a caracterização microestrutural das amostras, que foram embutidas em resina fenólica de cura a quente, e a seguir foram lixadas com lixas de granulometria de \#220 a \#600 com posterior polimento com pasta de diamante de granulação de 6 e $1 \mu \mathrm{m}$. A seção observada foi a longitudinal da chapa.

As amostras polidas foram atacadas com reagente químico Nital $2 \%$. Após ataque as amostras foram analisadas no microscópio eletrônico de varredura CAMSCAN CS3200LV do CDMatM-FEI, de onde foram obtidas imagens elétrons secundários das amostras atacadas para auxílio da caracterização microestrutural. Para a determinação da fração volumétrica de martensita, foram obtidas 20 imagens de elétrons secundários por amostra. Após a obtenção das imagens, procedeu-se à análise de imagens com o auxílio do software computacional Olympus AnaliSys.

\section{RESULTADOS}

A Figura 2 apresenta as imagens de elétrons secundários das amostras. Na Figura 2 (a) segue apresentada a microestrutura da amostra como recebida, onde se nota a presença de ilhas de martensita dispersas na matriz ferrítica $(\alpha)$. A microestrutura das amostras tratadas termicamente é apresentada da Figura $2(b-d)$, a medida que a temperatura de recozimento aumenta, um aumento na quantidade de ilhas de martensita presente é observado. Além disso, nota-se em todas as imagens das

\footnotetext{
* Contribuição técnica ao 69 Congresso Anual da ABM - Internacional e ao 14ํㅡㄹ ENEMET - Encontro Nacional de Estudantes de Engenharia Metalúrgica, de Materiais e de Minas, 21 a 25 de julho de 2014, São Paulo, SP, Brasil.
} 


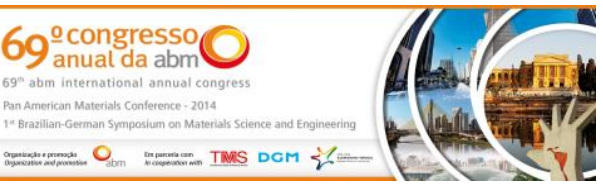

amostras tratadas a presença de possíveis precipitados formados durante o tratamento térmico, já que estes não foram observados na condição como recebida.

A fração de martensita obtida para cada condição segue apresentada na Tabela 2. O aumento da fração de martensita observado na Figura 2 é confirmado nos resultados quantitavos apresentados. A amostra na condição como recebida apresenta valores próximos aos encontrado para amostra recozida intercriticamente a $740^{\circ} \mathrm{C}$.

Tabela 2 - Fração de martensita.

\begin{tabular}{c|c}
\hline Identificação & Fração vol. de martensita [\%] \\
\hline Como recebida & $33,32 \pm 1,48$ \\
$720^{\circ} \mathrm{C}$ & $11,53 \pm 2,36$ \\
$730^{\circ} \mathrm{C}$ & $12,71 \pm 1,49$ \\
$740^{\circ} \mathrm{C}$ & $34,46 \pm 2,24$ \\
\hline
\end{tabular}

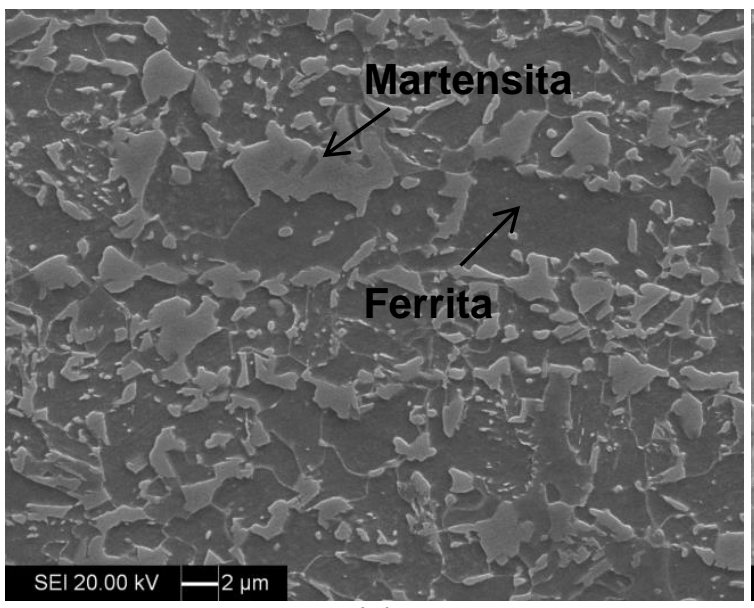

(a)

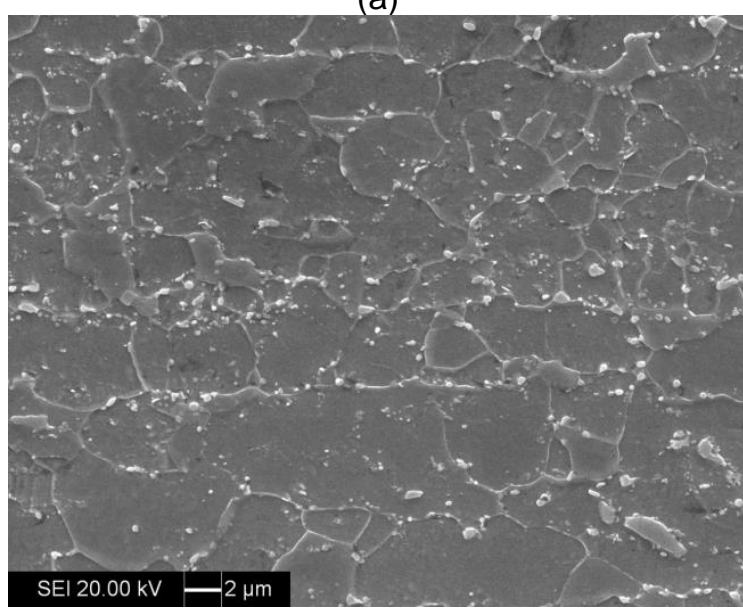

(c)

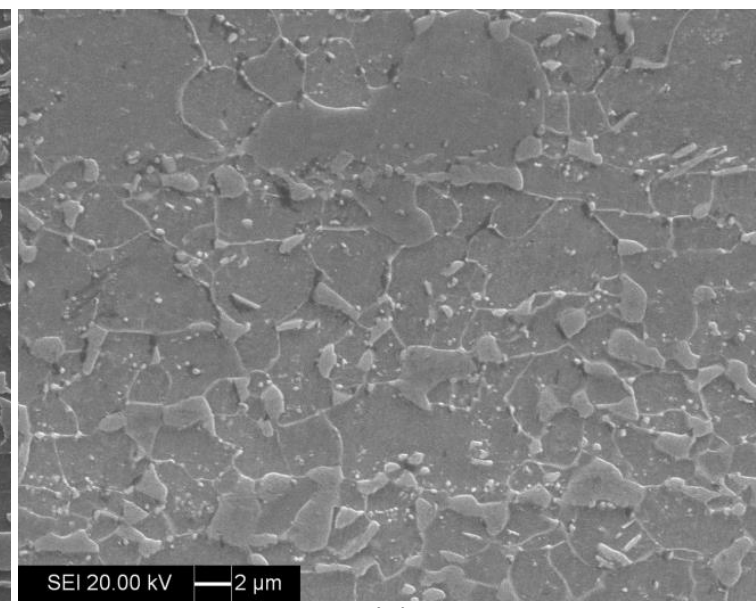

(b)

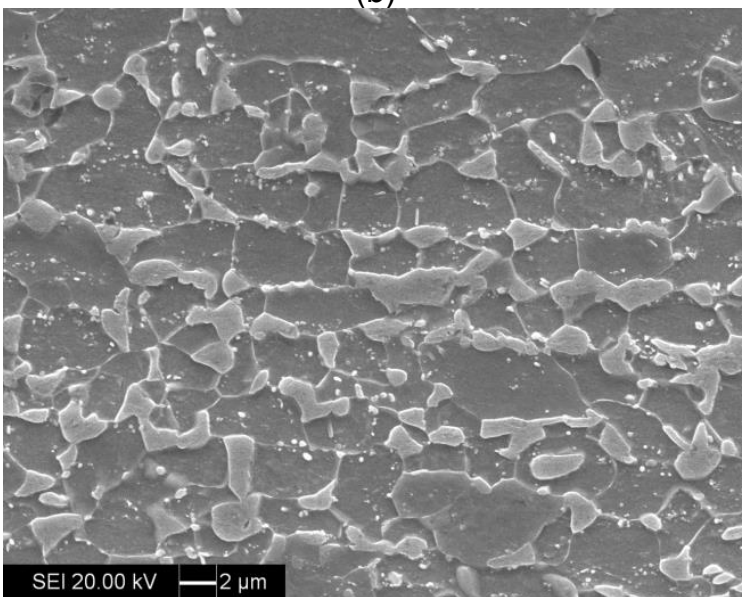

(d)

Figura 2. Imagens de elétrons secundários das amostras. (a) como recebido. (b) tratada a $720^{\circ} \mathrm{C}$. (c) tratada $730^{\circ} \mathrm{C}$. (d) tratada a $740^{\circ} \mathrm{C}$.

As propriedades mecânicas de interesse obtidas no ensaio de tração seguem apresentadas na Tabela 3. Nota-se nas amostras tratadas termicamente aumento nos limites de resistência e escoamento com o aumento da temperatura de recozimento intercrítico, paralelamente se observa a diminuição dos alongamentos,

* Contribuição técnica ao 69ำ Congresso Anual da ABM - Internacional e ao 14ํㅡㄹ ENEMET - Encontro Nacional de Estudantes de Engenharia Metalúrgica, de Materiais e de Minas, 21 a 25 de julho de 2014, São Paulo, SP, Brasil. 
total e uniforme. Os valores de escoamento e resistência registrados para a condição como recebida são menores que os reportados para as amostras tratadas, em contrapartida os alongamentos, total e uniforme, apresentam valores superiores.

Tabela 3 - Propriedades mecânicas obtidas pelo ensaio de tração.

\begin{tabular}{c|c|c|c|c}
\hline Identificação & $\begin{array}{c}\text { Limite de } \\
\text { escoamento }\end{array}$ & $\begin{array}{c}\text { Limite de } \\
\text { resistência }\end{array}$ & $\begin{array}{c}\text { Alongamento } \\
\text { total }\end{array}$ & $\begin{array}{c}\text { Alongamento } \\
\text { uniforme }\end{array}$ \\
\hline & LE (MPa) & LR (MPa) & At-50 mm (\%) & $\varepsilon u(-)$ \\
\hline Como recebida & $516 \pm 2,28$ & $812 \pm 5,38$ & $29,7 \pm 0,42$ & $0,20 \pm 0,006$ \\
$720^{\circ} \mathrm{C}$ & $562 \pm 13,41$ & $951 \pm 19,38$ & $14,2 \pm 0,35$ & $0,12 \pm 0,007$ \\
$730^{\circ} \mathrm{C}$ & $584 \pm 17$ & $968 \pm 10,79$ & $10,1 \pm 0,19$ & $0,09 \pm 0,01$ \\
$740^{\circ} \mathrm{C}$ & $650 \pm 1,45$ & $1073 \pm 5,37$ & $9,0 \pm 0,58$ & $0,07 \pm 0,02$ \\
\hline \hline
\end{tabular}

A partir do ensaio de embutimento Erichsen foram obtidos os dados apresentados na Figura 3. Nota-se que a medida que a temperatura de tratamento térmico aumenta tem-se a diminuição da profundidade de estampagem no ensaio. A amostra como recebida apresentou valores de profundidade de estampagem próximos ao apresentado pela amostra recozida intercriticamente a $720^{\circ} \mathrm{C}$.

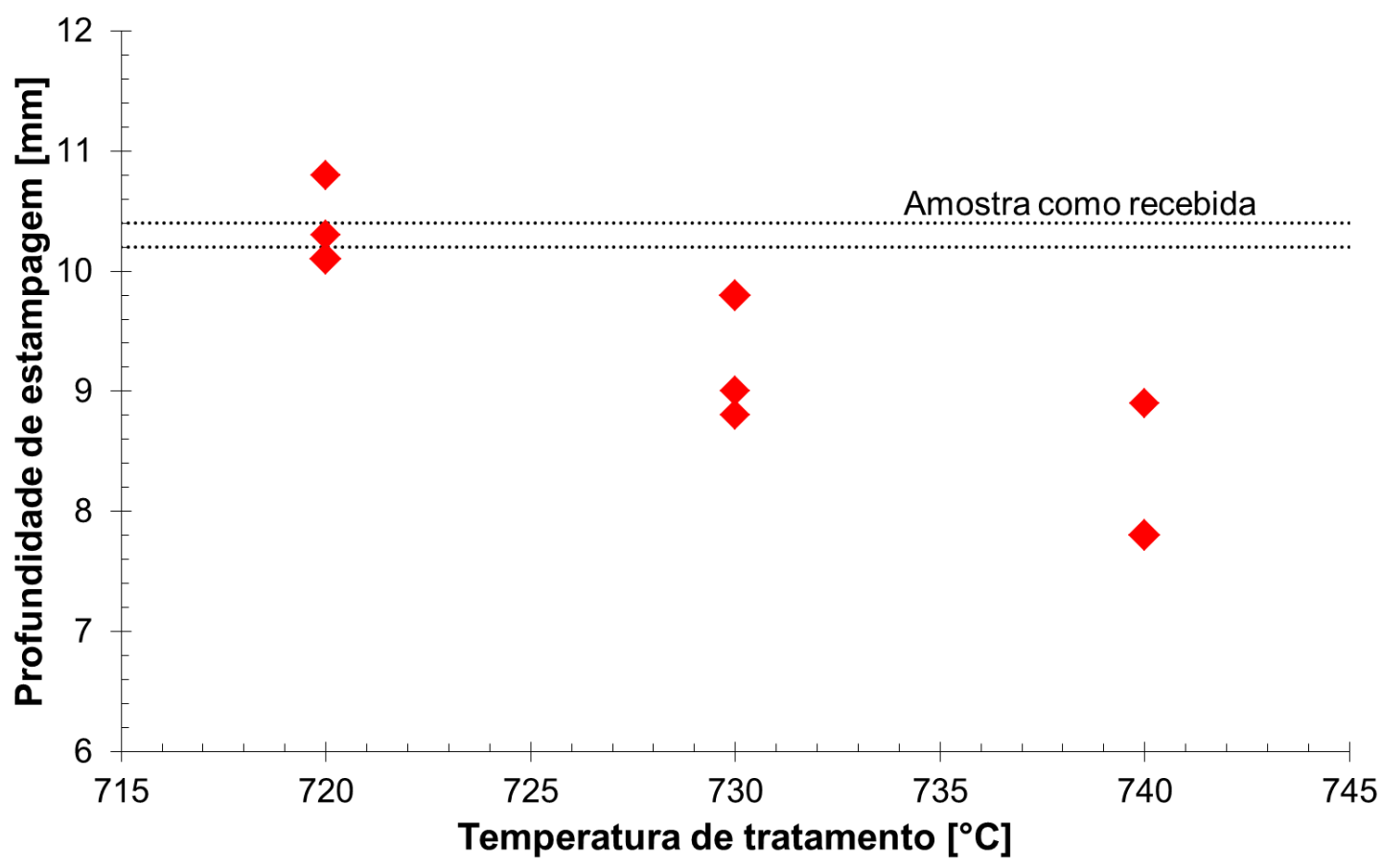

Figura 3. Profundidade de estampagem em função da temperatura de tratamento.

\section{DISCUSSÃO}

Com o auxilio do software CES EduPack ${ }^{\circledR}$ versão 2013, foi obtido o gráfico apresentado na Figura 4, e em sua construção foram considerados todos os aços micro-ligados pertencentes a base de dados. Nota-se que os aços Dual-Phase apresentam a melhor combinação de alongamento e resistência, conforme sugerido por Davies e Magee [3]. O aço em estudo encontra-se destacada em vermelho. Nota-se que as propriedades por ele apresentadas, $800 \mathrm{MPa}$ e 29,7\%, estão de

* Contribuição técnica ao $69^{\circ}$ Congresso Anual da ABM - Internacional e ao 14ํㅡㄹ ENEMET - Encontro Nacional de Estudantes de Engenharia Metalúrgica, de Materiais e de Minas, 21 a 25 de julho de 2014, São Paulo, SP, Brasil. 


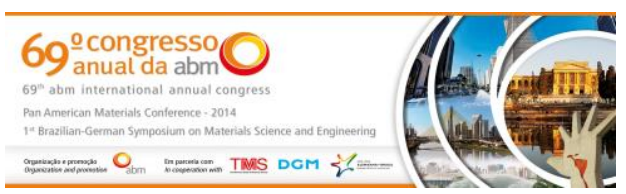

acordo com o apresentado por outros dual-phase, destacando-se um maior alongamento.

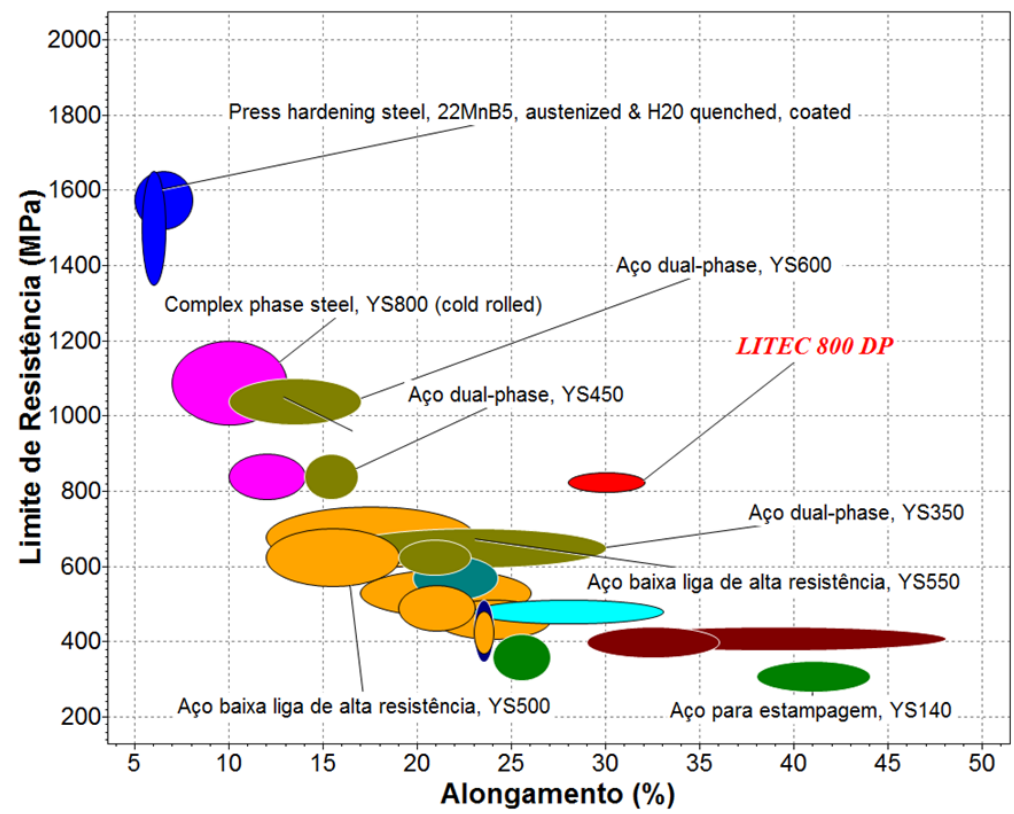

Figura 4. Alongamento em função da resistência atração.

$\mathrm{Na}$ avaliação da microestrutura das diferentes amostras, elaborou-se um diagrama comparativo da fração de austenita determinada pelo programa ThermoCalc ${ }^{\circledR}$ e da fração de martensita obtida, em função da temperatura de tratamento intercrítico. apresentado na Figura 5.

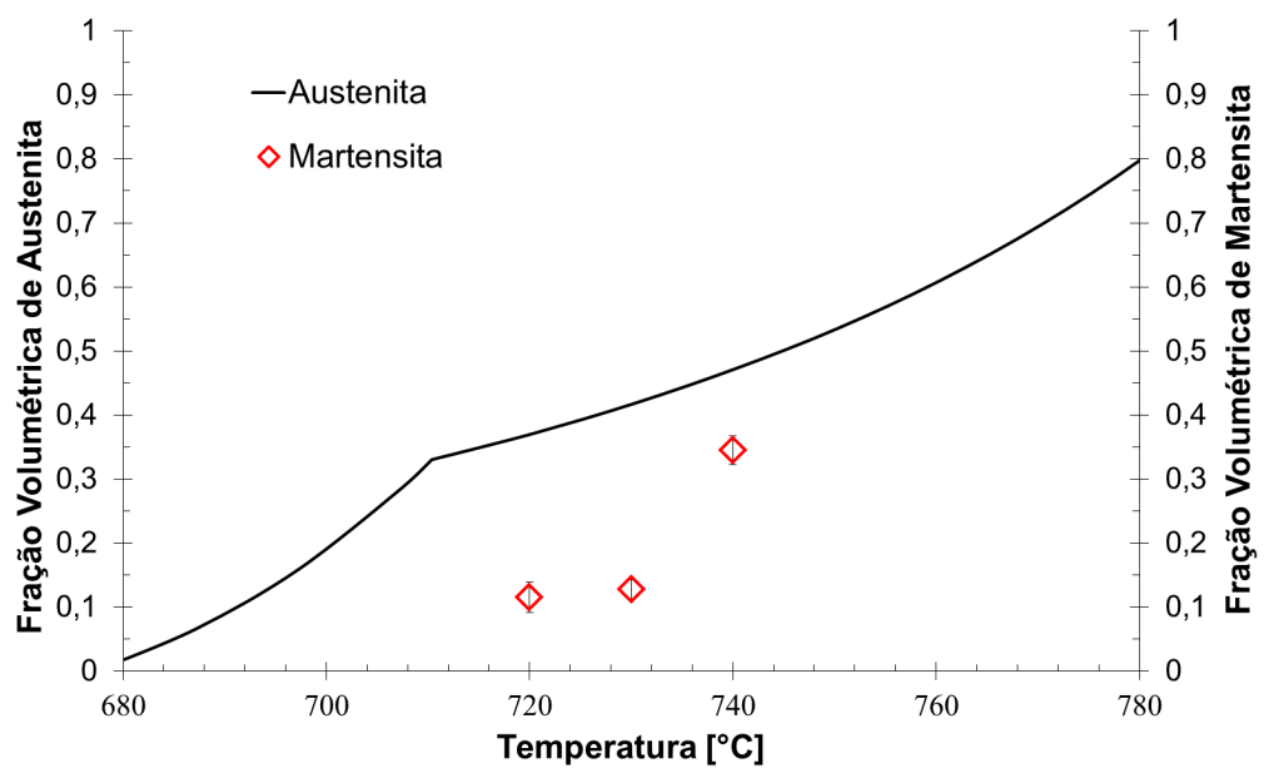

Figura 5. Comparação da fração em volume de austenita simulada no Thermo-Calc em relação a fração de martensita medida por estereologia quantitativa.

Nota-se que as frações obtidas para as amostras tratadas encontram-se abaixo da estimada pela simulação indicando que o tempo de tratamento térmico pode não ter sido suficiente para que o equilíbrio entre as fases, ferrita e austenita, fosse atingido, como já demonstrado em simulações de cinética de austenitização intercrítica de aço dual-phase [2].

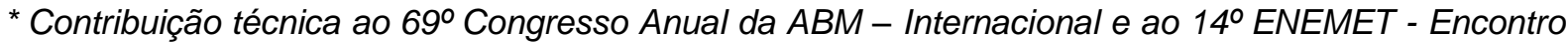
Nacional de Estudantes de Engenharia Metalúrgica, de Materiais e de Minas, 21 a 25 de julho de 2014, São Paulo, SP, Brasil. 
$\mathrm{Na}$ análise da microestrutura das amostras, Figura 2, e da fração de martensita obtida, Tabela 3, nota-se que a fração de martensita obtida para amostra tratada a $740^{\circ} \mathrm{C}$ é muito próxima daquela apresentada pelo material como recebido, entretanto, a morfologia apresentada por estas amostras, Figura 2 (a) e (d) difere. As ilhas de martensita apresentada na amostra do material com recebido encontram-se numa distribuição homogênea na matriz ferrítica, enquanto que na amostra recozida intercriticamente a $740^{\circ} \mathrm{C}$ as ilhas de martensita encontram-se alternadas com os grãos de ferrita. Ainda analisando Figura 2 nota-se a presença de constituintes menores, estes constituintes podem ser melhor visualizados na Figura 6. Foi realizada análise de EDS na amostra tratada a $730^{\circ} \mathrm{C}$ para a verificação da composição química nos pontos indicados na Figura 6. As composições químicas determinadas seguem apresentada na Tabela 4, cujos espectros são apresentados na Figura 7. Nota-se na análise um aumento dos picos de carbono, manganês e cromo em relação à matriz ferrítica, entretanto, não se pode afirmar que estes constituintes são carbonetos já que a solubilidade do carbono e do manganês na austenita é maior que na ferrita, levando, portanto a um aumento destes elementos na primeira fase e por consequência na martensita formada a partir da austenita.

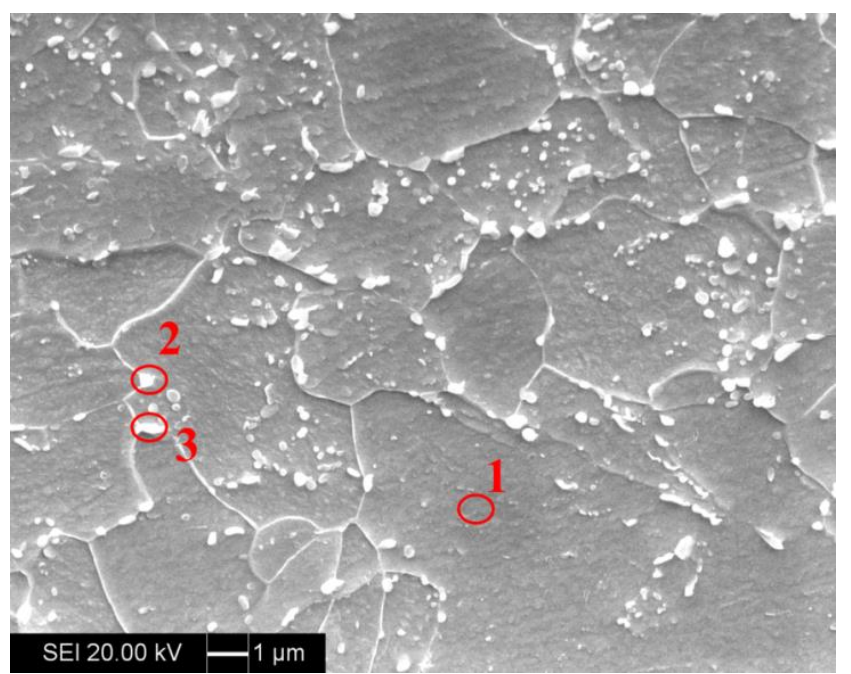

Figura 6. Imagens de elétrons secundários do aço dual-phase em estudo recozido intercriticamente a $730^{\circ} \mathrm{C}$.

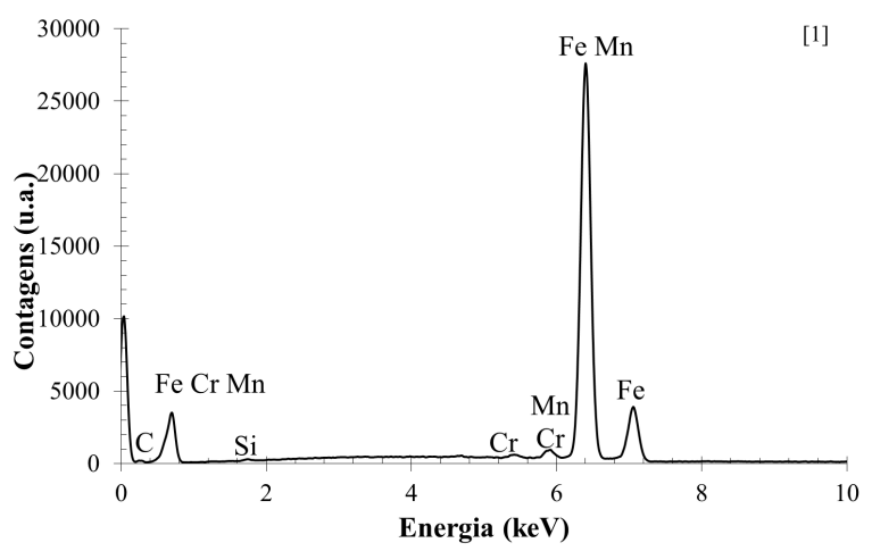

(a)

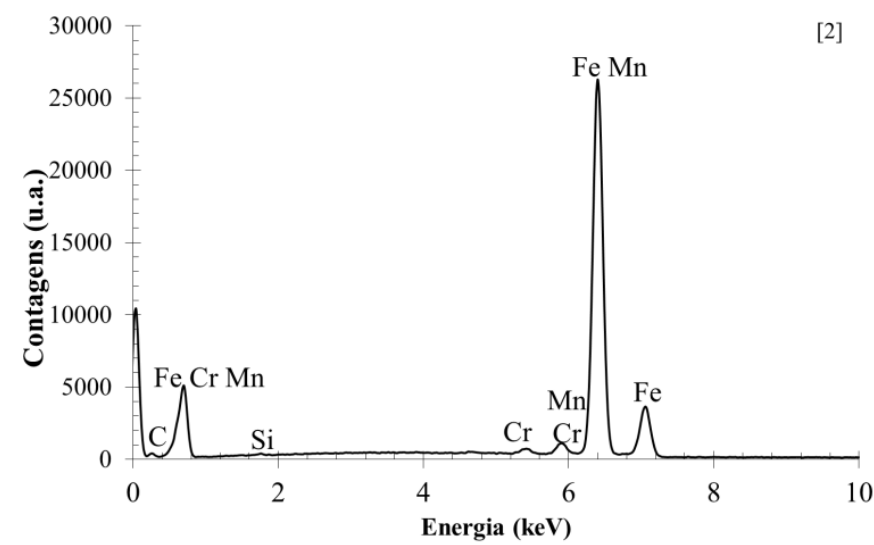

(b)

* Contribuição técnica ao $69^{\circ}$ Congresso Anual da ABM - Internacional e ao 14ํㅡㄹ ENEMET - Encontro Nacional de Estudantes de Engenharia Metalúrgica, de Materiais e de Minas, 21 a 25 de julho de 2014, São Paulo, SP, Brasil. 

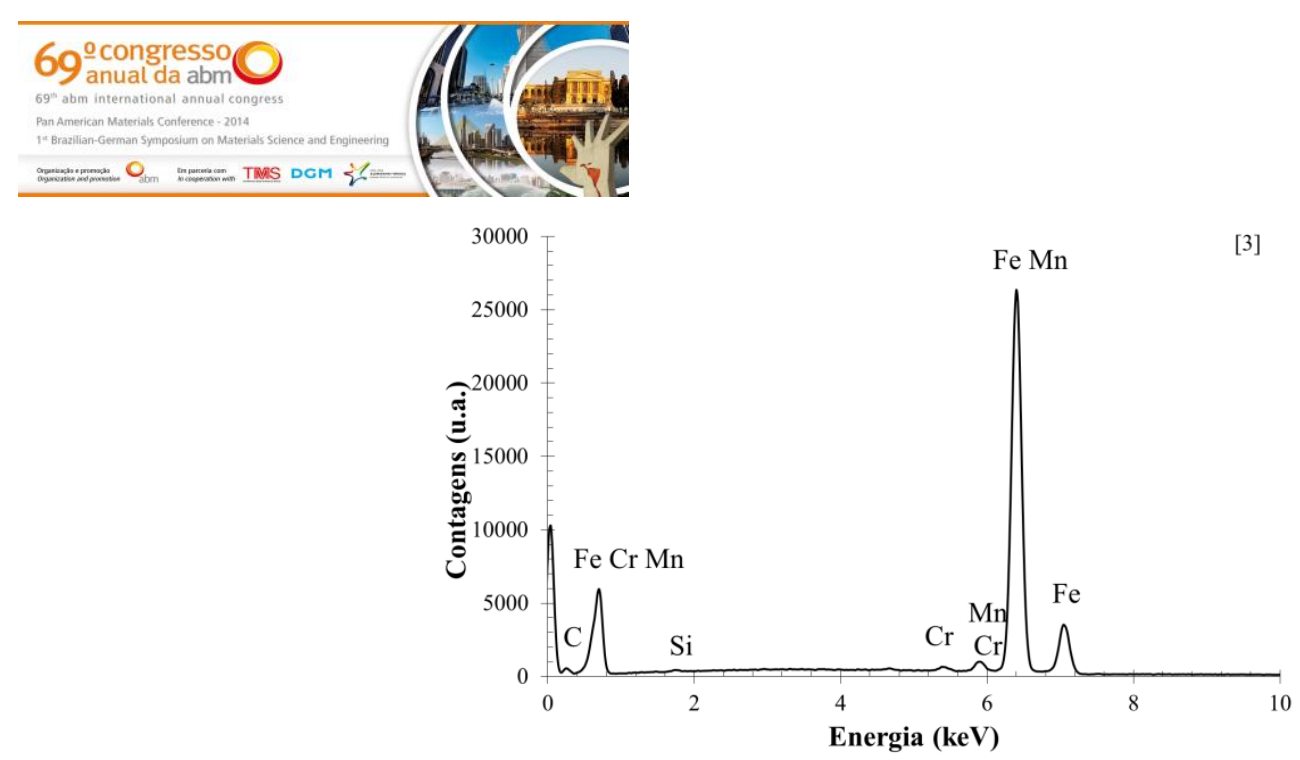

(c)

Figura 7. Espectros de EDS dos pontos (a) 1, (b) 2 e (c) 3 da Figura 6.

Tabela 4. Quantificação por EDS dos pontos da Figura 16, referentes a amostra tratada termicamente a $730^{\circ} \mathrm{C}$.

\begin{tabular}{cccc}
\hline Posição & Si (\%p) & $\operatorname{Cr}(\% p)$ & Mn (\%p) \\
\hline$(1)$ & $0,17 \pm 0,03$ & $0,45 \pm 0,04$ & $1,69 \pm 0,08$ \\
\hline$(2)$ & $0,15 \pm 0,03$ & $0,7 \pm 0,05$ & $2,23 \pm 0,08$ \\
\hline$(3)$ & $0,18 \pm 0,05$ & $0,54 \pm 0,05$ & $1,98 \pm 0,08$ \\
\hline
\end{tabular}

Como uma segunda análise avalia-se a influência da temperatura de tratamento nas propriedades mecânicas do aço em estudo, para isto correlacionou-se a fração de martensita, que é função da temperatura, com as respostas mecânicas obtidas no ensaio de tração. As variações do limite de escoamento e do limite de resistência com a fração de martensita seguem apresentadas nas Figuras 8 e 9, respectivamente. Analisando somente o comportamento das amostras tratadas termicamente, nota-se que o aumento da fração de martensita levou ao aumento dos limites de escoamento e resistência. Apesar da amostra tratada termicamente a $740^{\circ} \mathrm{C}$ apresentar fração de martensita semelhante a do material como recebido, o escoamento e a resistência apresentados pelo material tratado são superiores ao do último. Segundo Kim e Thomas [11] a diferença de morfologia e distribuição das fases, ferrita e martensita, em aços dual-phase afetam significativamente as propriedade mecânicas do material, o que pode justificar a diferença de propriedades observadas.

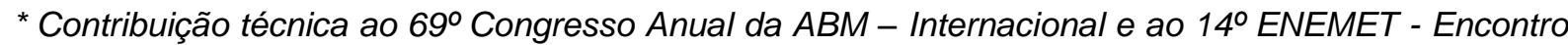
Nacional de Estudantes de Engenharia Metalúrgica, de Materiais e de Minas, 21 a 25 de julho de 2014, São Paulo, SP, Brasil. 

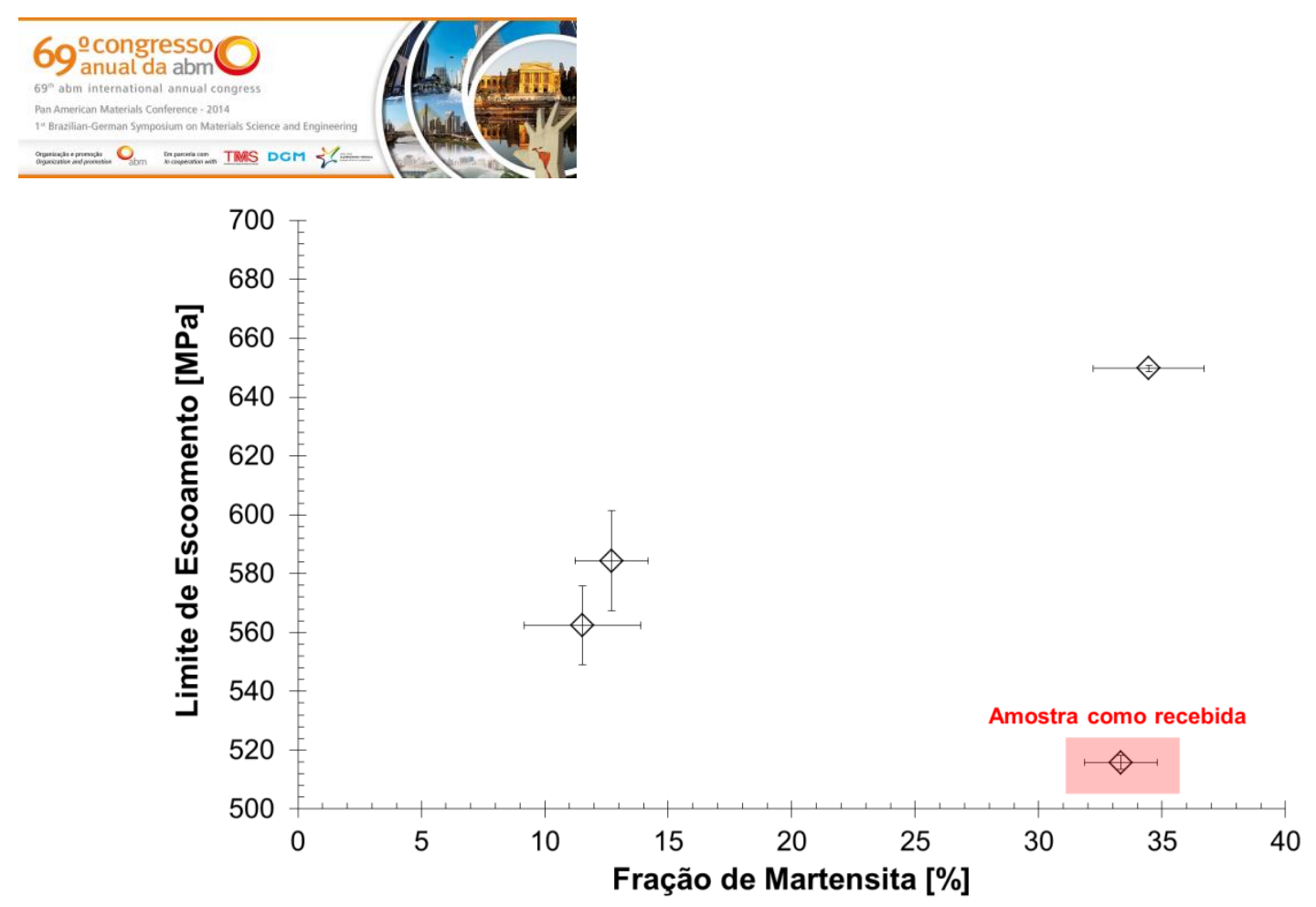

Figura 8. Limite Escoamento em função da fração de martensita.

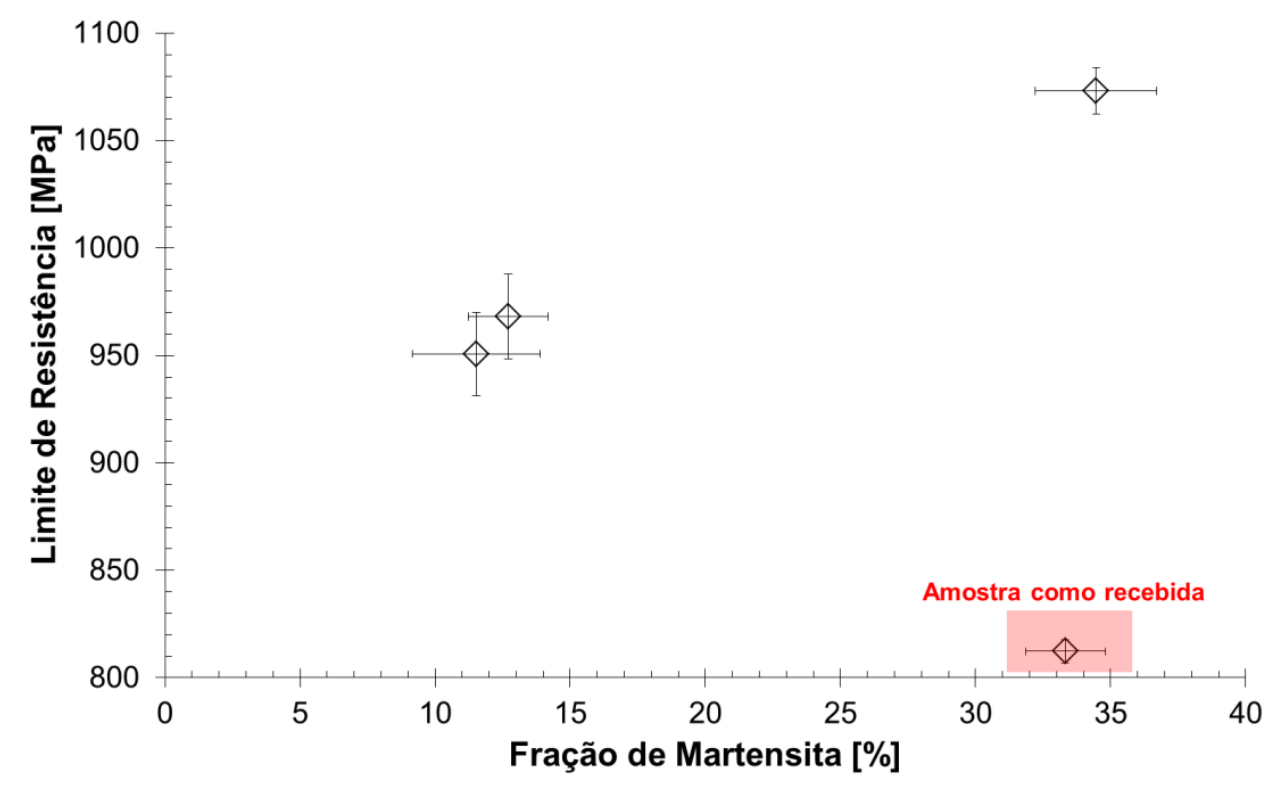

Figura 9. Limite Resistência em função da fração de martensita.

As Figuras 10 e 11 apresentam a variação dos alongamentos, total e uniforme, com a fração de martensita. Observa-se que para as amostras tratadas termicamente 0 alongamento diminui com o aumento da fração de martensita, entretanto novamente observa-se que apesar das amostras tratada a $740^{\circ} \mathrm{C}$ e como recebida apresentarem a mesma fração de martensita os valores de alongamento divergem, sendo que a amostra como recebida apresenta alongamento significativamente superior ao da tratada a $740^{\circ} \mathrm{C}$. Novamente os fatores morfológicos podem ter influenciado na resposta mecânica.

* Contribuição técnica ao 69ํ Congresso Anual da ABM - Internacional e ao 14을 ENEMET - Encontro Nacional de Estudantes de Engenharia Metalúrgica, de Materiais e de Minas, 21 a 25 de julho de 2014, São Paulo, SP, Brasil. 

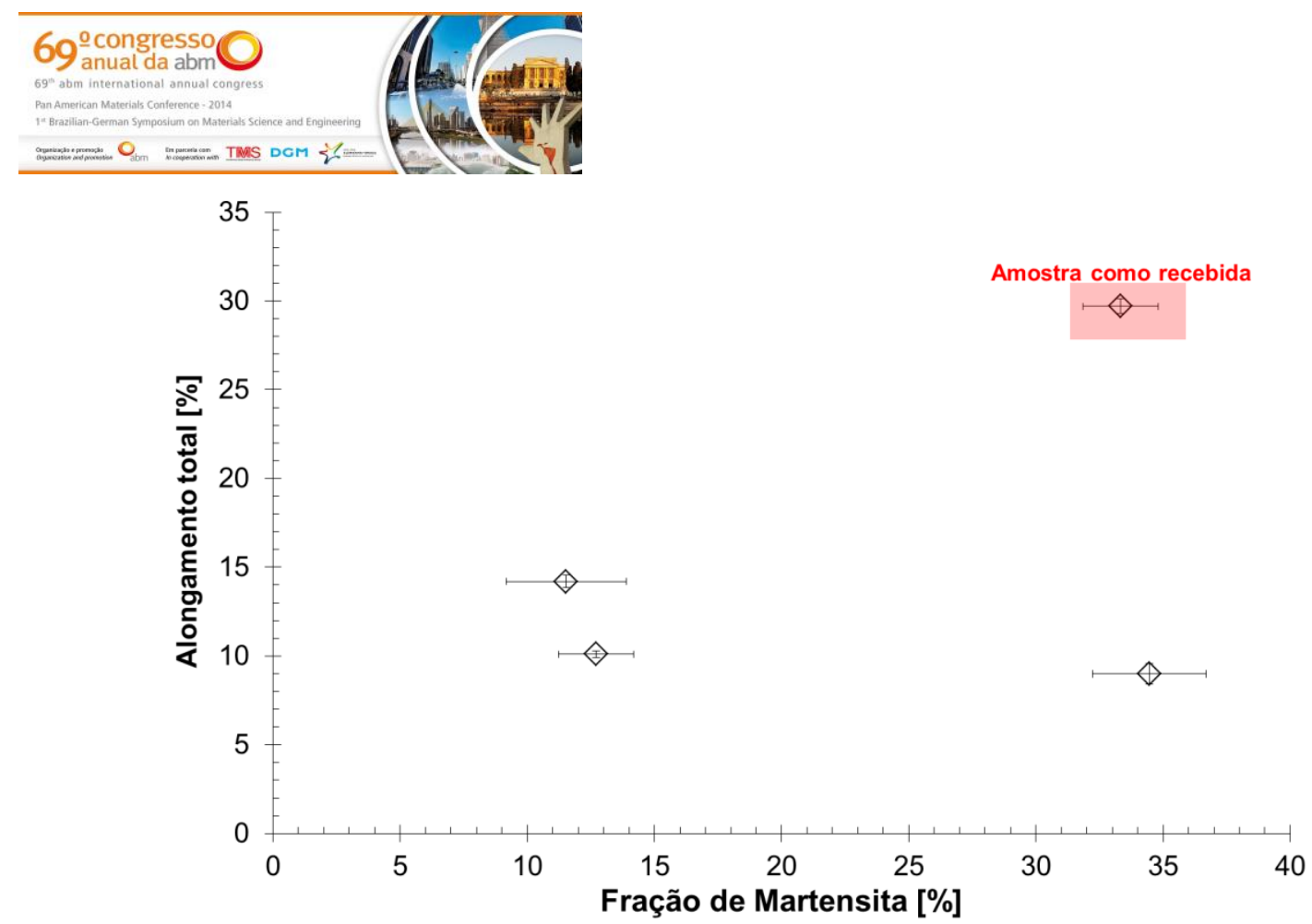

Figura 10. Variação do alongamento total em função da fração de martensita.

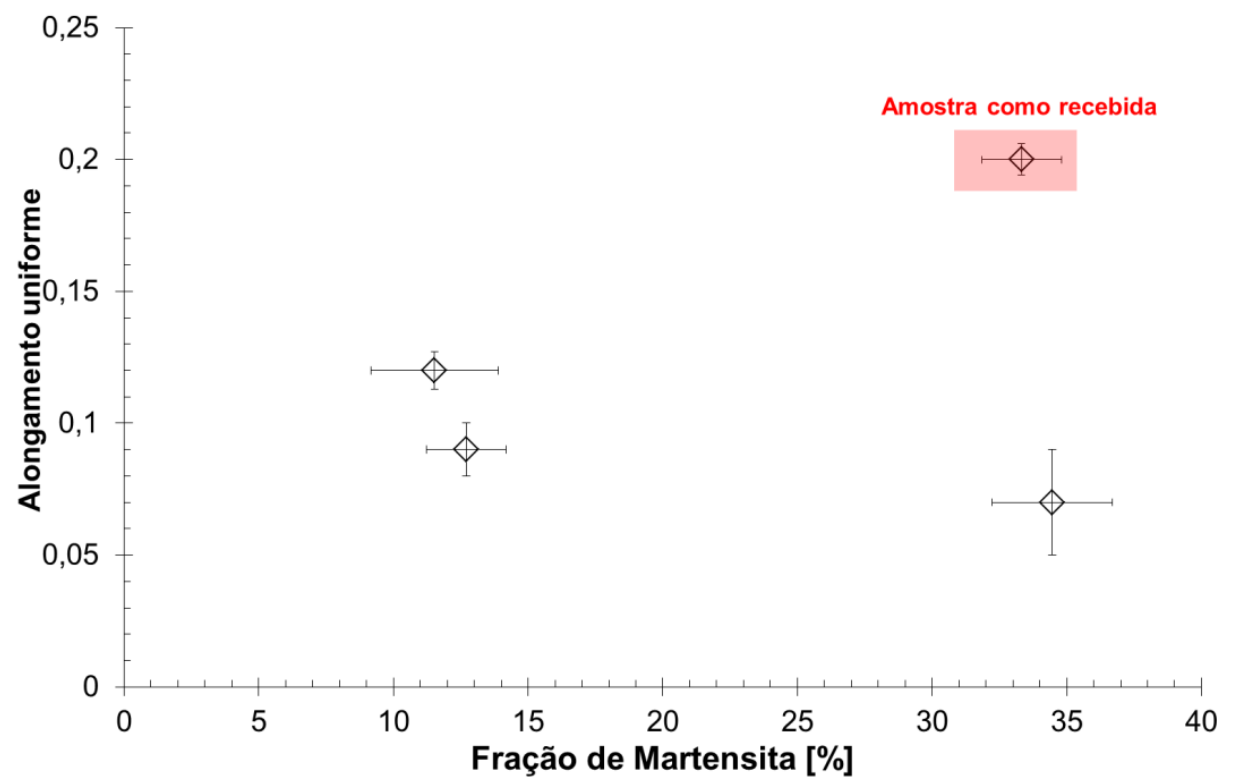

Figura 11. Variação do alongamento uniforme em função da fração de martensita.

A variação da profundidade de estampagem com a fração de martensita encontra-se apresentada na Figura 12. Nota-se que o aumento da profundidade de estampagem diminui com o aumento da fração de martensita, exceto para amostra na condição como recebida que apresenta uma alta fração de martensita com profundidade de estampagem próxima da apresentada para amostra com aproximadamente $11 \%$ de martensita.

\footnotetext{
* Contribuição técnica ao 69 Congresso Anual da ABM - Internacional e ao 14ํㅡㄹ ENEMET - Encontro Nacional de Estudantes de Engenharia Metalúrgica, de Materiais e de Minas, 21 a 25 de julho de 2014, São Paulo, SP, Brasil.
} 

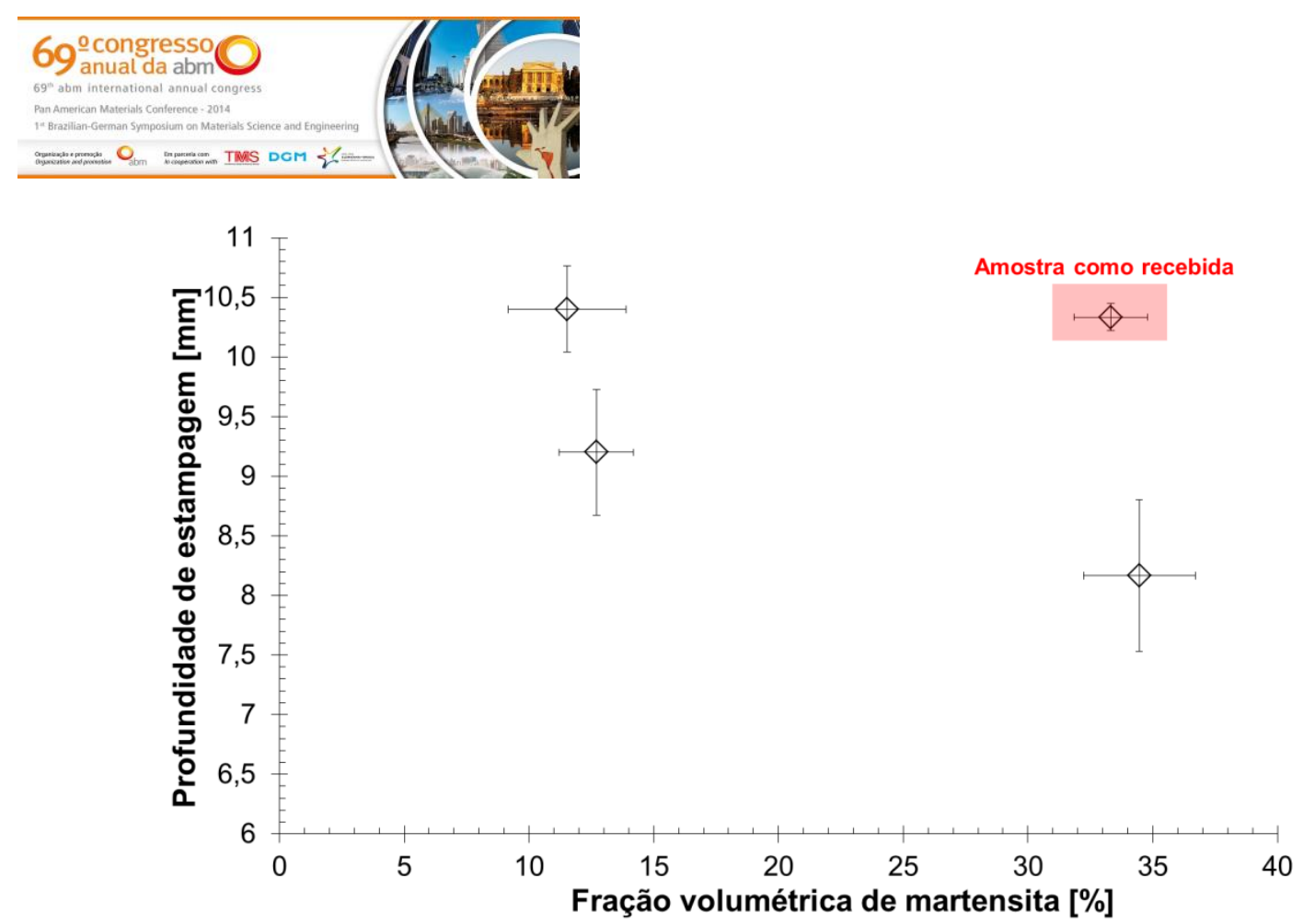

Figura 12. Profundidade de estampagem em função da fração de martensita.

A partir da análise realizada no presente trabalho, nota-se que a condição que apresenta melhor combinação entre resistência mecânica, ductilidade e melhor desempenho na estampagem é a amostra como recebida, na condição de produção da usina, sem o tratamento isotérmico de recozimento intercrítico. As diferenças de valores observadas sugerem que a amostra na condição como recebida provavelmente não foi obtida pelo processo de recozimento intercrítico, dadas diferenças morfológicas e de propriedades aqui relatadas. Como discutido na introdução deste trabalho, os aços dual-phase podem ser obtidos por outros processos, como por exemplo, laminação controlada e recozimento contínuo. Visto que os aços dual-phase são utilizados principalmente na indústria automotiva onde é necessária alta resistência com boa estampabilidade, o processo de fabricação do material de partida resulta em melhor desempenho do que os obtidos por recozimento intercrítico já que os valores de resistência encontrados foram cerca de $812 \mathrm{MPa}$ combinado a um alongamento total de $29,7 \%$, além dos valores de estampabilidade serem próximos ao obtido na amostra com $11 \%$ porém com uma fração de $33 \%$ de martensita na estrutura.

\section{CONCLUSÕES}

Do presente trabalho pode-se concluir que:

1. O aumento da fração de martensita levou ao aumento da resistência e do limite de escoamento e em consequência a diminuição dos alongamentos, total e uniforme, exceto para o material de partida que apresentou fração de martensita próxima à da amostra tratada a $740^{\circ} \mathrm{C}$, entretanto com menores valores de resistência e escoamento e maiores alongamentos.

2. A diferença de morfologia apresentada pelo material de partida levou a diferentes respostas mecânicas em relação a amostra tratada a $740^{\circ} \mathrm{C}$, apesar da semelhante fração de martensita.

3. O processo de fabricação do aço dual-phase como recebido apresenta melhor combinação entre resistência, alongamento, estampabilidade e, portanto, para aplicação no setor automotivo.

\footnotetext{
* Contribuição técnica ao $69^{\circ}$ Congresso Anual da ABM - Internacional e ao 14ํㅡㄹ ENEMET - Encontro Nacional de Estudantes de Engenharia Metalúrgica, de Materiais e de Minas, 21 a 25 de julho de 2014, São Paulo, SP, Brasil.
} 


\section{Agradecimentos}

Os autores agradecem as empresas Ruukki e a PCP steel pela concessão do material utilizado no presente trabalho.

\section{REFERÊNCIAS}

1 Hansen SS, Pradhan RR. Structure/ Properties Relationships and Continues Yielding behavior in Dual-phase Steels.Fundamentals of Dual-phase steels, USA, S.1, p. 113114, Feb. 1981.

2 Forgas A, Magnabosco R. Influência do Tempo de Recozimento Intercrítico na Microestrutura de um Aço Bifásico Baixo Carbono. In: Congresso Internacional Anual Da ABM, 65, 2010, Belo Horizonte. Anais...

3 Davies RG, Magee CL. Physical Metallurgy of Automotive High Strength Steels. Fundamental of Dual-phase steels. USA, p. 1-18, 1979.

4 Cohen M; Hansen SS. On the Fundamentals of Dual-Phase Steels.HSLA Steels: Metallurgy and Aplications, China, 1985: 61-70.

5 Gorni AA. Aços Avançados de Alta Resistência: Microestrutura e Propriedades Mecânicas. In: Congresso de Corte e Conformação de Metais, 5, 2009, São Paulo. Anais...

6 Silveira VHM, Schaeffer L. Estampagem de Chapas de Alta Resistência para Uso Automotivo - Parte 1. Siderurgia Brasil, v.71, abr. 2011.

7 Speich GR, Miller RL. Mechanical Properties of Ferrite-Martensite Steels.Fundamental of Dual-phase steels.USA, p. 3-45, 1979.

8 Forgas A, Magnabosco R. Influência da Temperatura de Recozimento Intercritico no Comportamento Mecânico de um Aço Bifásico Baixo Carbono. In: Congresso Internacional Anual da ABM, 64, 2009, Belo Horizonte. Anais...

9 ASTM E8M-13a. Standard Test Methods for Tension Testing of Metallic Materials.ASTM - American Society for Testing and Materials. Philadelphia, USA, 2013.

10 ASTM E 643-09.Standard Test Method for Ball Punch Deformation of Metallic Sheet Material.ASTM - American Society for Testing and Materials. Philadelphia, USA, 2009.

$11 \mathrm{Kim}$ NJ, Thomas G. Effects of Morphology on Mechanical Behavior of Dual Phase Fe/2Si/0,1C Steel.Metallurgical Transactions: 12: 483 - 489.

12 Software Cambridge Engineering Selector - CESEduPack (www.grantadesign.com).

* Contribuição técnica ao 69ํ Congresso Anual da ABM - Internacional e ao 14ํㅡㄹ ENEMET - Encontro Nacional de Estudantes de Engenharia Metalúrgica, de Materiais e de Minas, 21 a 25 de julho de 2014, São Paulo, SP, Brasil. 